\title{
Effect of Coaxing on the Fatigue StrengtJi of Spheroidal and Compa Graphite Cast Iron
}

nasir kloub, A.R.I Kheder

\begin{abstract}
In this research the effect of coaxing on the fatigue strength of spheroidal and compacted graphite cast iron was studied. The stress-stress cycle curves for both irons were established and the fatigue limits (6॰v) were deterrnined. They were $185 \mathrm{MPa}$ for spheroidal graphite cast iron (SGI) and $175 \mathrm{MPa}$ for compacted graphite cast iron (CGI). Then samples were subjected to two step loading; namely low-high loading. The initial loading was $182 \mathrm{MPa}$ for SGI which is lower than the for SGI by $3 \mathrm{MPa}$ and the initial loading was $172 \mathrm{MPa}$ for CGI which is lower than 6 for CGI by $3 \mathrm{MPa}$. For both irons the tests were run for $7 \times 10 *$ cycles at the lower range of loading until the cracks started to appear and stopped from growing, then specimens were subjected to higher stresses; namely 220 MPa for SGI and 210 MPa for CGI until failure of the specimens occurred. The results obtained for the coaxing phenomenon in SGI showed 8.96 folds improvement and 7.34 folds for CGI in fatigue life. The tests were done at room temperature at a stress ratio of $\mathrm{R}=\mathbf{- I}$. The specimens were in form of strips which were subjected to alternating bending fatigue test.
\end{abstract}

